\title{
Senna (Leguminosae, Caesalpinioideae) na Floresta Nacional de Silvânia, Goiás, Brasil
}

\author{
Senna (Leguminosae, Caesalpinioideae) in the National Forest Silvânia, Goiás, Brazil
}

\author{
Alessandro Oliveira de Souza ${ }^{1,2}$ \& Marcos José da Silva ${ }^{1}$
}

\begin{abstract}
Resumo
Senna é o segundo maior gênero da subfamília Caesalpinioideae com aproximadamente 300 espécies, das quais 80 ocorrem no Brasil. A taxonomia das espécies brasileiras de Senna é pouco estudada, particularmente daquelas presentes na região Centro-Oeste. Este trabalho objetivou o levantamento taxonômico das espécies de Senna ocorrentes na Floresta Nacional de Silvânia, Goiás. Foram encontradas nove espécies o que corresponde a 10\% das espécies do gênero ocorrentes no Brasil e 37\% presentes no estado de Goiás. São fornecidas chave de identificação, descrições, comentários sobre distribuição geográfica, semelhanças morfológicas e fenologia, além de imagens com caracteres diagnósticos para oito das nove espécies.
\end{abstract}

Palavras-chave: Cassiinae, diversidade, florística, taxonomia.

\begin{abstract}
Senna is the second largest genus in the subfamily Caesalpinioideae with 300 species, of which 80 occur in Brazil. The taxonomy of the Brazilian species of Senna is poor studied, particularly in the Midwest of country. This study aimed to the taxonomic survey of the species of Senna occurring in the National Forest Silvânia, Goiás. We found nine species which corresponds to $10 \%$ of the species occurring in Brazil and $37 \%$ present in the State of Goiás. We provided identification key, descriptions, comments about geographical distribution, morphological similarities and, phenology, as well as images to eight species.
\end{abstract}

Key words: Cassiinae, diversity, floristic, taxonomy.

\section{Introdução}

Senna é um gênero monofilético (Marazzi et al. 2006) e o segundo maior de Leguminosae subfamília Caesalpinioideae com cerca de 300 espécies com distribuição pantropical (Lewis et al. 2005). No Brasil está representado por aproximadamente 81 espécies, sendo 33 delas endêmicas (BFG 2015). Senna pertence à tribo Cassieae, subtribo Cassiinae juntamente com os gêneros Cassia L. e Chamaecrista Moench, diferenciando-se dos mesmos pelas folhas com nectários entre os pares de folíolos ou peciolares convexos, estames heteromórficos com filetes não sigmóides e anteras usualmente rostradas, além de não apresentar bractéolas no pedicelo (Irwin \& Barneby 1982).

As obras clássicas de Bentham (1871) na Flora Brasiliensis e Irwin \& Barneby (1982) são os principais estudos sobre o gênero no Brasil. Além destes, alguns estudos sobre Senna foram realizados para floras locais ou estaduais (Lewis 1987; Lima 1999; Rodrigues et al. 2005; Bortoluzzi et al. 2007; Queiroz 2009; Santos 2013). Mesmo assim, o conhecimento da taxonomia de suas espécies em áreas de Cerrado do Brasil central é ainda escasso.

Este trabalho objetivou o levantamento taxonômico das espécies de Senna ocorrentes na Floresta Nacional de Silvânia, Goiás, visando contribuir com o conhecimento florístico do bioma Cerrado, especialmente no estado de Goiás.

\section{Material e Métodos}

A Floresta Nacional de Silvânia (FLONASilvânia) é uma das Unidades de Conservação do estado de Goiás (Fig. 1), situa-se no município de Silvânia e possui uma área de aproximadamente 487,37 ha. Seu clima é Aw (Köppen 1948), com temperatura média de $23^{\circ} \mathrm{C}$, período chuvoso de

\footnotetext{
${ }^{1}$ Universidade Federal de Goiás, Inst. Ciências Biológicas, Depto. Botânica, Campus Samambaia II, C.P. 131, 74001-970, Goiânia, GO, Brasil.

${ }^{2}$ Autor para correspondência: alessandro341@hotmail.com
} 

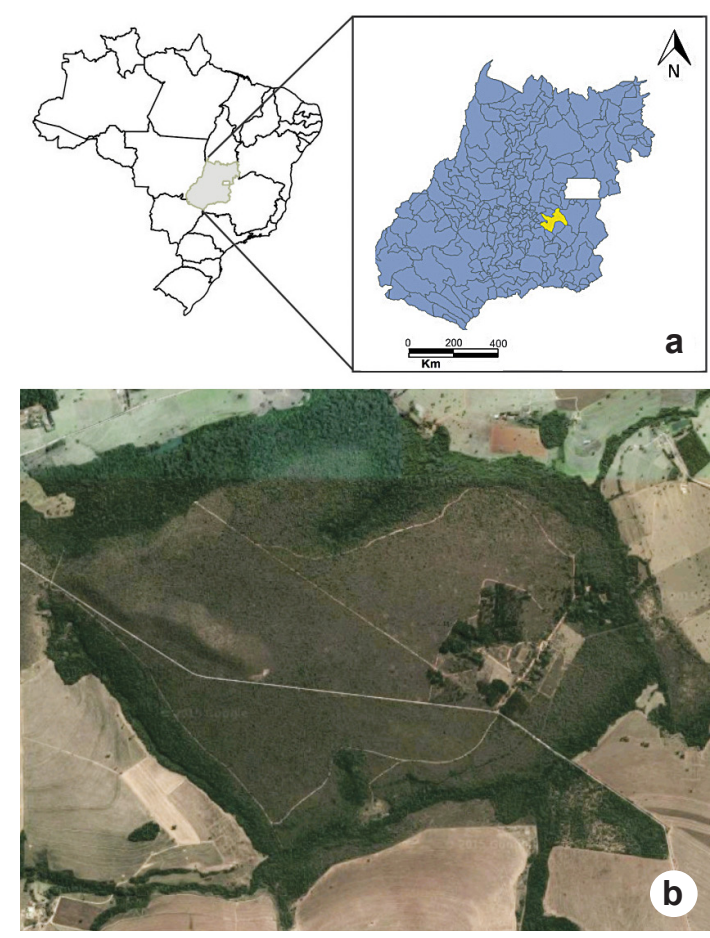

Figura 1 - a. mapa com os limites do município de Silvânia (GO) em amarelo; b. área da região da FLONA-Silvânia. Figure 1 - a. map with the limits of the municipality of Silvânia (GO) in yellow; b. area of FLONA-Silvânia region.

outubro a março e seco e frio de abril a setembro. As formações vegetacionais da FLONA-Silvânia compreendem Campo sujo, Cerrado sensu stricto, florestas semideciduais e de galeria distribuídas em uma altitude média de $900 \mathrm{~m}$. Foram realizadas excursões mensais à área estudada no período de maio de 2012 a agosto de 2013 para obtenção de material botânico seguindo as recomendações de Mori et al. (1989), e observação das populações em seus habitats. Durante as expedições foram coletadas amostras férteis de cada individuo, além de registros fotográficos. Concomitantemente flores foram fixadas em álcool $70 \%$ para auxiliar a identificação e descrição das espécies. $\mathrm{O}$ material coletado, após herborização encontra-se depositado no Herbário UFG. A identificação das espécies baseou-se em Irwin \& Barneby (1982) e a descrição do gênero e das espécies com base na variação morfológica de seus indivíduos. Comentários sobre distribuição, geográfica, fenologia e ambientes preferenciais das espécies resultaram de observações das mesmas em seus habitats, consulta a etiquetas de exsicatas herborizadas e literatura. As descrições foram realizadas com auxílio de estereomiscrocópio Zeiss. O mapa foi elaborado no software QGIS 2.8.2 e imagens provenientes do Google Earth. A maioria das fotografias é de autoria dos próprios autores, quando não, os créditos foram indicados nas legendas. A terminologia de frutos aqui adotada segue Dudik (1981).

\section{Resultados e Discussão}

Senna Mill., Gard. Dict. Abr. ed. 4, v. 3.1754.

Subarbustos, arbustos ou árvores, eretos ou decumbentes. Ramos glabros ou indumentados. Estípulas persistentes ou caducas. Folhas compostas, paripinadas, alternas espiraladas, pecioladas; folíolos 2-30 pares, opostos com formas, consistência e dimensões variadas, nervação broquidódroma; nectário extrafloral, quando presente, peciolar ou entre os pares de folíolos (interfoliolar), ovóides, clavados, subulados, globosos ou cilíndricos. Racemos ou panículas, axilares ou terminais, laxas ou congestas. Botões globoides a obovoides. Flores zigomorfas ou assimétricas, pediceladas, dialissépalas; 5-meras, as pétalas amarelas e heteromórficas, sendo uma posterior, duas postero-laterais e duas antero-laterais; androceu heteromórfico, estames 10 , sendo (2-)3 abaxiais (2 latero-abaxiais e 1 centro-abaxial), semelhantes em tamanho ou não, 4 medianos e 3 estaminódios, anteras poricidas; ovário oblongoide, estipitado, puntiforme a claviforme. Legumes planos a cilíndricos, oblongos a lineares, tardiamente deiscentes ou indeiscentes. Sementes retangulares a elipsóides, castanho-claras a escuras, arranjadas em uma ou duas séries.

Neste estudo Senna está representado por nove espécies o que corresponde a $10 \%$ das espécies do gênero presentes no Brasil e 37\% daquelas ocorrentes no estado de Goiás (BFG 2015).

\section{Chave para os táxons de Senna da Floresta Nacional de Silvânia}

1. Folhas sem nectários, pétalas com mácula vermelha na base.

8. S. silvestris subsp. bifaria var. bifaria

1'. Folhas com nectários, pétalas não maculadas. 
2. Folhas com 10-30 pares de folíolos.

3. S. multijuga

2'. Folhas com 2-6 pares de folíolos.

3. Folhas com exatamente 2 pares de folíolos.

4. Nectário apenas no primeiro par de folíolos; folíolos membranáceos a papiráceos .9. S. splendida

4'. Nectários nos dois pares de folíolos; folíolos cartáceos ou coriáceos.

5. Árvore; pecíolo 2,8-5 cm compr.

1. S. macranthera

5. Subarbusto à arbusto; pecíolo menor que $2,5 \mathrm{~cm}$ compr.

7. S. rugosa

3'. Folhas com 3-6 pares de folíolos.

6. Folhas com nectário peciolar; folíolos com ápices acuminados; estame centro-abaxial vestigial 5. S. occidentalis

6'. Folhas com nectário interfoliolares; folíolos com ápices obtusos; estame centro-abaxial não vestigial.

7. Folhas com 4-6 pares de folíolos; racemos típicos 4-7 cm compr; legumes oblongoides, cilíndricos. 6. S. pendula var. glabrata

7'. Folhas com 3 pares de folíolos; racemos umbeliformes 0,5-1,2 cm compr; legumes lineares, ligeiramente cilíndricos ou quadrangulares.

8. Folíolos com a face abaxial densamente pubescente a tomentosa; flores 4-6 cm compr.; pétalas 2,3-3,5 cm compr.; estames abaxiais de tamanhos semelhantes, $17-19 \mathrm{~mm}$ compr. 2. S. mucronifera

8. Folíolos glabros a glabrescentes em ambas faces; flores $1-2,7 \mathrm{~cm}$; pétalas $0,7-1,2$ cm compr.; estames abaxiais de tamanho desiguais, os latero-abaxiais 5-7 mm compr. e o centro-abaxial $2-3 \mathrm{~mm}$ compr. 4. S. obtusifolia

1. Senna macranthera (Collad.) H.S. Irwin \& Barneby, Mem. New York Bot. Gard. 35: 181. 1982.

Fig. 2a-c

Árvores 3-9 m alt. Ramos, pecíolo, raque, face abaxial dos folíolos, pedicelo, face externa das sépalas e brácteas tomentelo-dourados. Estípulas caducas. Folhas 10,5-20,1 cm compr.; pecíolo $2,8-5 \mathrm{~cm}$ compr.; raque $2,2-4 \mathrm{~cm}$ compr.; folíolos 2 pares, 4,8-12,4 × 3-6 cm, oblongoobovais ou oblongo-elípticos, conspicuamente assimétricos, ápice obtuso ou agudo, base oblíqua, discolores, face adaxial verde-escura, puberulenta a tomentosa, face abaxial verdeopaca, tomentosa, margem ligeiramente revoluta, cartáceos; nervuras amareladas e proeminentes na face abaxial. Nectários 7-1,2 mm compr., ovoides a cônicos ou oblongoides, nos dois pares de folíolos. Panículas 10,5-20,7 cm compr., axilares e terminais, laxas com mais de 6 flores. Brácteas 3-4 mm compr., ovais. Flores 3,4-6,5 $\mathrm{cm}$ compr., assimétricas; pedicelo $2,2-3,5 \mathrm{~cm}$ compr.; sépalas $4-6 \times 3 \mathrm{~mm}$, ovais; pétalas 1,7-3,2 × 1,3-2 cm, oblongas ou oblongoobovais, não maculadas; estames abaxiais 3 , 12-22 mm compr., semelhantes, medianos $8-10$ $\mathrm{mm}$ compr., rostro da antera $0,1-0,2 \mathrm{~mm}$ compr., estaminódios 3-5 mm compr.; ovário 1,7-3 cm compr., linear-oblongo, tomentelo; estilete ca. 4 mm compr. Legumes $16-33 \times 1-2,4$ cm compr., indeiscentes, cilíndricos, retos, enegrecidos quanto maturos, estipe $0,6-0,9 \mathrm{~cm}$ compr. Sementes não observadas.

Material examinado: Acima do alojamento da FLONA, 04.II.2013, fl., A.O. Souza et al. 119 (UFG); ao lado da sede entre os eucaliptos, 13.III.2013, fl., A.O. Souza et al. 188 (UFG).

Espécie sulamericana (Brasil, Colômbia, Equador, Peru e Venezuela), sendo no Brasil encontrada em todas as regiões, como nativa no Cerrado sensu lato e caatinga entre 100-1600 metros (Irwin \& Barneby 1982; Santos 2013; BFG 2015), ou cultivada como ornamental. Neste estudo foi encontrada acima do alojamento em área perturbada e em borda de Cerrado sensu stricto, com flores de fevereiro a março.

Senna macranthera pode ser reconhecida pelo porte arbóreo, ramos tomentoso-dourados e folhas com nectários nos dois pares de folíolos, os quais possuem base assimétrica e ápice agudo ou curtamente acuminado. Tais caracteres permitem diferenciá-la de $S$. splendida e $S$. rugosa, espécies mais semelhantes pelas folhas com apenas dois pares de folíolos e frutos cilíndricos. 
2. Senna mucronifera (Mart. ex Benth) H.S. Irwin \& Barneby, Mem. New York Bot. Gard. 35: 247. 1982.

Fig. 3a-c

Subarbustos $0,6-1 \mathrm{~m}$ alt., eretos, pouco ramificados. Ramos, estípulas e pecíolo pubescentes a tomentelos ou glabrescentes. Estípulas 5-10 mm compr., linear-elípticas ou lanceoladas, ápice acuminado, persistentes. Folhas 5,3-10,5 cm compr.; pecíolo 1,3-3,1 cm compr.; raque 1,1-2,6 cm compr.; folíolos 3 pares, 1,5-5
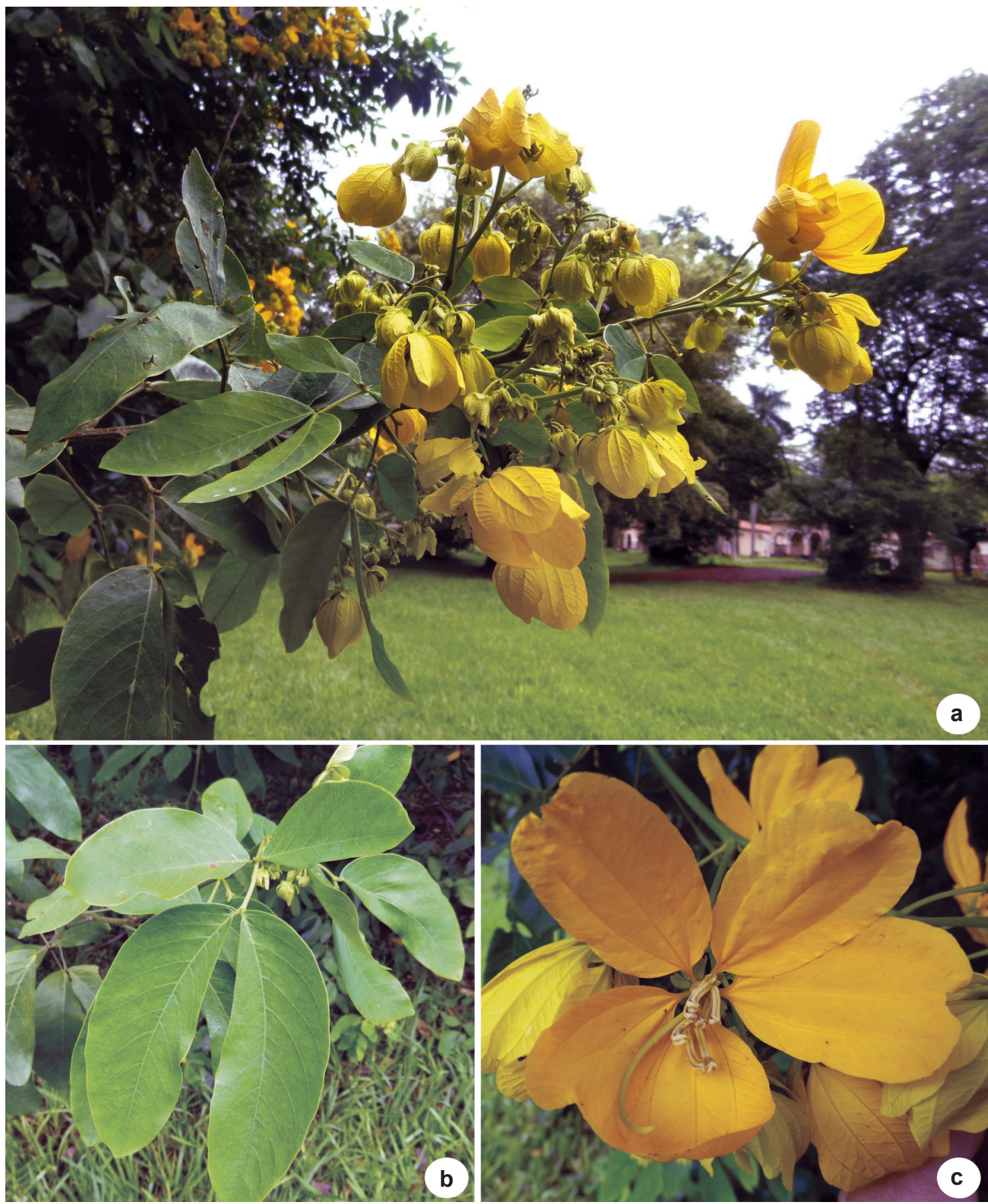

Figura 2 - a-c. Senna macranthera - a. ramo com flores; b. folha; c. flor.

Figure 2 - a-c. Senna macranthera - a. flowering branch; b. leaf; c. flower. 


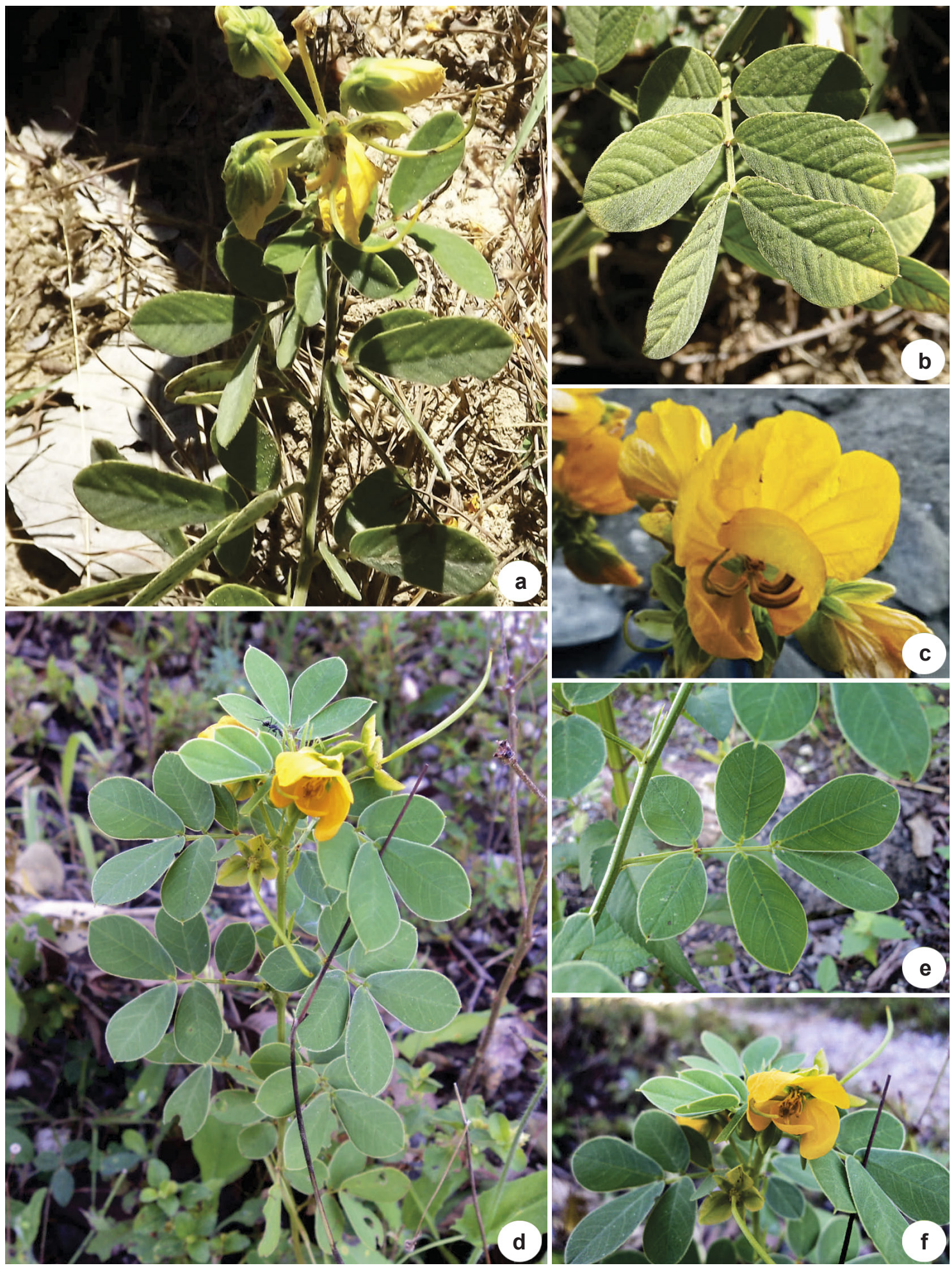

Figura 3 - a-c. Senna mucronifera - a. ramos com flores; b. folha; c. flor. d-f. Senna obtusifolia - d. ramos com flores; e. folha; f. flor. (Fotografias a-c concedidas por Josimar P. Santos).

Figure 3 - a-c. Senna mucronifera - a. flowering branch; b. leaf; c. flower. d-f. Senna obtusifolia - d. flowering branch; e. leaf; f. flower (Photographs a-c granted by Josimar P. Santos). 
$\times 1-2,8 \mathrm{~cm}$, obovais, ápice obtuso, raro truncado e mucronulado, base oblíqua, discolores, face adaxial verde-escuro e puberulento, face abaxial verde-opaca e densamente pubescente a tomentosa, membranáceos a tênues cartáceos. Nectários 1-3 $\mathrm{mm}$ compr., subulados, nos dois pares de folíolos proximais, raramente no par distal. Racemos $0,5-1,2 \mathrm{~cm}$, umbeliformes, axilares com 1 ou 2 flores. Brácteas 2-4 × 0,3-0,4 mm, ovais, lineares, persistentes. Flores 4-6 cm compr., assimétricas; pedicelo $2-3,3 \mathrm{~cm}$ compr., sépalas $0,8-1,8 \times$ $0,5-1,8 \mathrm{~cm}$, oval-oblongas a oblongo-elípticas; pétalas 2,3-3,5 × 1,5-2,1 cm, obovais a elípticas, a antero-lateral esquerda oblongo-falcada, não maculadas; estames abaxiais $3,1,7-1,9 \mathrm{~cm}$ compr., semelhantes, medianos $0,8-1 \mathrm{~cm}$ compr., rostro da antera 2-3 mm compr., estaminódios 3-4 mm compr.; ovário 2-2,13 × 0,7-1,1 cm, glabrescente a tomentoso, estilete $5,1-6,3 \mathrm{~cm}$ compr., estigma punctiforme. Legumes $15-16 \times 0,2-0,3 \mathrm{~cm}$, lineares, quadrangulares a ligeiramente cilíndricos, verdes, curvos. Sementes não vistas.

Material examinado: Trilha acima do córrego a esquerda da sede em meio à transição de cerradão e mata seca, 20.XI.2012, f1., A.O. Souza et al. 31, 42 e 44 (UFG).

Espécie com registro para o Brasil, Bolívia, Paraguai e Venezuela, onde cresce em cerrado s.l. e nas florestas estacionais (Irwin \& Barneby 1982; Santos 2013), ambientes em que também foi coletada neste estudo. Floresce de março a agosto e frutifica em junho.

Senna mucronifera compartilha com $S$. obtusifolia o hábito subarbustivo e ereto, as folhas com 3 pares de folíolos obovais membranáceos a tênue cartáceos, estípulas linear-lanceoladas e racemos umbeliformes. No entanto, S. mucronifera diferencia-se de $S$. obtusifolia pela face abaxial dos folíolos densamente pubescente a tomentosa (vs. glabros em S. obtusifolia), flores com 4-6 cm compr. (vs. 1-2,7 cm), além dos estames abaxiais de tamanho semelhantes com 1,7-1,9 cm compr. (vs. estames abaxiais desiguais os lateroabaxiais 5-7 mm compr. e o centro-abaxial 2-3 mm compr.).
3. Senna multijuga (Rich.) H.S. Irwin \& Barneby, Mem. New York Bot. Gard. 35: 492. 1982.

Árvores 3-5 m alt., tronco com casca áspera e acinzentada. Ramos, estípulas pecíolo, raque, peciólulo, nervura principal, margem dos folíolos, eixo da inflorescência, brácteas, pedicelo e face externa das sépalas esparsos a densamente tomentelo-douradas. Estípulas 3,5-15 × 2-7 mm, linear-lanceoladas com base dilatada, retorcidas ou não. Folhas 6,4-22,5 cm compr.; pecíolo 1,1-3,5 cm compr.; raque 3,3-20,4 cm compr.; folíolos 10-30 pares, $14-40 \times 3-12 \mathrm{~mm}$, oblongos ou oblongo-elípticos, ápice obtuso e mucronulado, base ligeiramente oblíqua, pilosulos em ambas as faces, discolores, face adaxial verde-escuro, face abaxial verde-clara opaca, margem ligeiramente revoluta, membranáceos a papiráceos. Nectários 1-3 mm compr., subulados a clavados, nos pares de folíolos, mas comumente caducos na região mediana da folha. Panículas 6-14,5 cm compr., axilares e terminais com mais de 10 flores. Brácteas $4-6 \mathrm{~cm}$ compr., linear-elípticas. Flores 2,5-5,2 cm compr., assimétricas; pedicelo 1,5-3,3 cm compr.; sépalas 5-9 × 3-7 mm, oblongo-ovais a suborbiculares, ápice obtuso, amarelas; pétalas 1-3×0,6-1,5 cm, obovais, a antero-lateral direita maior e oblonga-falcada, não maculadas; estames abaxiais 3, 10-18 mm compr., semelhantes, medianos 6-10 mm compr., rostro da antera 1,5-2,2 mm compr. estaminódios ca. $4 \mathrm{~mm}$ compr.; ovário 5-12 × 1,5-2 mm, linear-oblongo; estilete 5-10 mm compr., glabro. Legumes 9-15,5 × $1-1,5 \mathrm{~cm}$, planos, oblongos, enegrecidos. Sementes 0,5-0,7 $\times 0,5 \mathrm{~mm}$, elipsoides, castanho-escuras.

Distribui-se desde a América do Norte até a América do Sul em Florestas Estacionais Semideciduais, Mata de Galeria e Cerrado s.l. No Brasil é reportado para todas as regiões como nativa ou cultivada (Irwin \& Barneby 1982; Dantas \& Silva 2013; BFG 2015).

Segundo Irwin \& Barneby (1982) esta espécie possui três subespécies: $S$. multijuga subsp. multijuga, S. multijuga subsp. lindleyana e S. multijuga subsp. doylei. Na FLONA-Silvânia ocorrem as duas primeiras sendo representadas pelas suas variedades típicas e diferenciadas pela a chave a seguir:

\section{Chave para as subespécies de Senna multijuga ocorrentes na Floresta Nacional de Silvânia}

1. Ramos densamente tomentoso-dourados; estípulas com base dilatada e retorcidas. 3.1. subsp. multijuga var. multijuga

1'. Ramos glabros a esparsamente tomentoso-dourados; estípulas retas

3.2. subsp. lindleyana var. lindleyana 
3.1 Senna multijuga subsp. multijuga var. multijuga. (Rich.) H.S. Irwin \& Barneby, Mem. New York Bot. Gard. 35: 492. 1982. Iconografia: Dantas \& Silva (2013: fig. 2e-i).

Táxon amplamente distribuído nas Américas. No Brasil é encontrada como nativa nas regiões Norte e Centro-Oeste entre 750-1000 metros (Irwin \& Barneby 1982; BFG 2015) ou cultivada ao longo do país. Na área de estudo foi coletada em cerrado na trilha ao norte da sede e na periferia desta última próximo a propriedades rurais sobre solos argilosos. Floresce de abril a novembro.

Material examinado: Trilha acima da entrada da sede, 20.XI.2012, fl., A.O. Souza, J.P. Santos et al. 28 (UFG); 29.IV.2013, fl., A.O. Souza et al. 334 (UFG); borda da mata próxima a fazenda a leste da sede, 25.V.2013, fl., A.O. Souza et al. 382 e 384 (UFG).

3.2 Senna multijuga var. lindleyana (Gardner) H.S. Irwin \& Barneby, Mem. New York Bot. Gard. 35: 498. 1982.

Táxon principalmente americano e distribuído de norte a sul do Brasil (BA, DF, GO, E S, MG, RJ, SP, PR, RS, SC), crescendo no Cerrado s.lat. e na Mata Atlântica entre 50-1800 m (Santos 2013; BFG 2015) ou cultivada. Neste estudo foi encontrado em bordas de florestas semideciduais sobre solos argilosos com flores em março.

Material examinado: Ao lado do casarão acima da sede, 13.III.2013, fl., A.O. Souza et al. 186 (UFG).

4. Senna obtusifolia (L.) H.S. Irwin \& Barneby, Mem. New York Bot. Gard. 35(1): 252. 1982. Iconografia: Dantas \& Silva (2013, fig. 3a-c).

Fig. 3d-f

Subarbustos $0,5-1 \mathrm{~m}$ alt., eretos. Ramos, pecíolo, raque, pedicelo e ambas as faces dos folíolos glabras a glabrescentes. Estípulas 4-15 $\mathrm{mm}$ compr., lineares ou linear-elípticas, ápice acuminado, pubescente, persistentes. Folhas 4-9,5 cm compr.; pecíolo 8-30 mm compr.; raque 9-23 mm compr.; folíolos 3 pares $1-4,4 \times 1,2-2,5 \mathrm{~cm}$, obovais,, ápice obtuso, base oblíqua, glabros, concolores, verde-oliváceos, tênues cartáceos. Nectários 1,2-3 mm compr., fusiformes a clavados, sésseis ou curtamente estipitados, usualmente no primeiro e às vezes no segundo par de folíolos. Racemos 0,5-1,2 cm compr., umbeliformes, axilares ou terminais com 2 ou 3 flores. Brácteas 3,5-6 mm compr., lineares, pubescentes. Flores 1-2,7 cm compr.; pedicelo $1-1,8 \mathrm{~cm}$ compr.; sépalas 4-8 × 2,5-5,5 mm, oblongas a ovais, ápice agudo, pubescentes externamente; pétalas $0,7-1,2$ $\times 0,6-0,8 \mathrm{~cm}$, obovais, a antero-lateral oboval- falcada, ápice obtuso a emarginado, não maculadas; estames abaxiais 3 , desiguais, os latero-abaxiais 5-7 mm compr. e o centro-abaxial 2-3 mm compr., medianos $4,5-5 \mathrm{~mm}$ compr., rostro da antera 0,2-0,8 mm compr., estaminódios ca. 4 mm compr.; ovário ca. $5 \mathrm{~mm}$ compr., oblongoide, seríceo; estilete curvo ca. $1 \mathrm{~cm}$ compr., seríceo. Legumes $6-14,5 \times 02-0,3 \mathrm{~cm}$, lineares, ligeiramente cilíndricos, curvos, verdes. Sementes não vistas.

Material examinado: Estrada de acesso a sede da FLONA antes da mata seca em local perturbado, 04.IV.2012, fl. e fr., M.M. Dantas201 e 202 (UFG); Imediações da sede da FLONA, 25.V.2013, fl. e fr., A.O. Souza et al. 373 (UFG).

Espécie americana (Irwin \& Barneby 1982) presente no Brasil em todas as regiões e crescendo em diversos tipos vegetacionais e também como invasora em locais alterados até 1680 metros (Irwin \& Barneby 1982; Santos 2013). Neste estudo foi encontrada como ruderal próximo à sede da FLONA com flores e frutos de abril a novembro.

Dentre as espécies estudadas Senna obtusifolia está mais relacionada morfologicamente com S. mucronifera com a qual compartilha o hábito subarbustivo, estípulas lineares, folhas com 3 pares de folíolos obovais e tênues cartáceos e racemos umbeliformes, mas é diferenciada pelas características já mencionadas nos comentários de S. mucronifera.

5. Senna occidentalis (L.) Link, Handbuch 2: 140. 1831. Iconografia: Dantas \& Silva (2013, fig. 3dg).

Fig. $4 a-c$

Subarbustos 60-80 cm alt., eretos. Ramos vináceos a verde-vinácos, glabros a puberulentos incluindo estípulas, pecíolo, raque, pedicelo e ambas as faces dos folíolos. Estípulas 3-6 × 1-2 mm, falcado-triangulares, ápice agudo ou acuminado. Folhas 16-25 cm compr., pecíolo 3,7-5,2 cm compr.; raque 5,5-12,3 cm compr.; folíolos 4-6 pares, 3,2-7,3 × 2-4 cm, oval-elípticos a elípticos, ápice acuminado, base oblíqua, discolores, verdeoliváceos na face adaxial e verde opacos na face abaxial, margem ciliada, membranáceos. Nectário 1-1,5 mm compr., globoso, na base do pecíolo. Racemos 2,5-3 cm compr., umbeliformes, axilares e terminais com 2-4 flores. Brácteas 2,9-3 mm compr., lineares ou lanceoladas. Flores 1,5-2,5 cm compr., zigomorfas; pedicelo 8-11 mm compr.; sépalas 7-9 × 3-5 mm, oblongas, ovais a oblongoelípticas, ápice agudo; pétalas 14-16 × 8-10 $\mathrm{cm}$, obovais a oblongo-obovais, não maculadas; estames abaxias 2, 10-12 mm compr., o centroabaxial vestigial, medianos 5-6 mm compr., rostro 

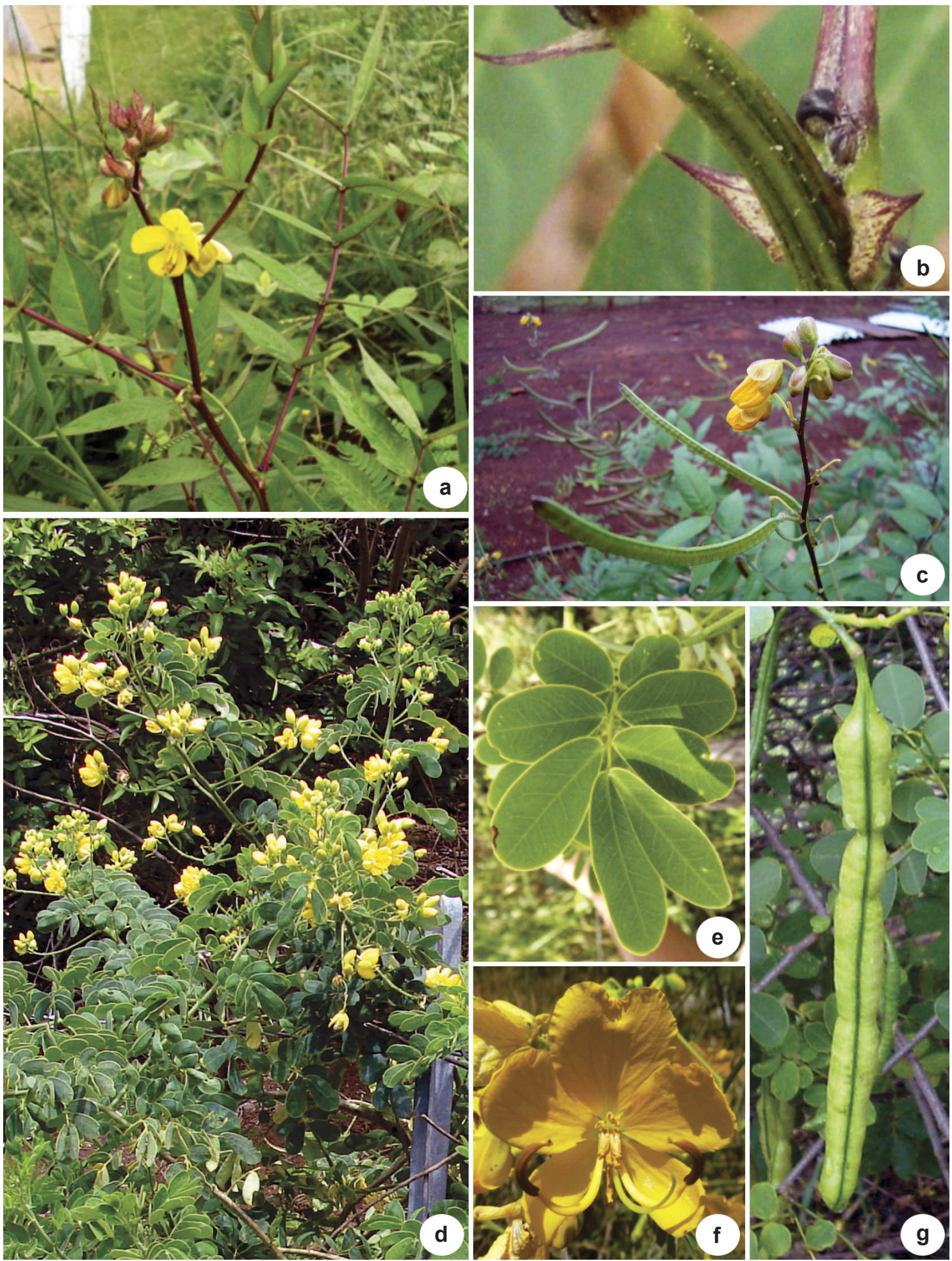

Figura 4 - a-c. Senna occidentalis - a. ramo com flores; b. detalhe mostrando estípulas e pecíolo com nectário; c. detalhe da inflorescência, flor e fruto. d-g. Senna pendula var. glabrata - d. ramo com flores; e. folha; f. flor; g. fruto (Fotografias a-d concedidas por Josimar P. Santos).

Figure 4 - a-c. Senna occidentalis - a. flowering branch; b. detail showing stipules and Petiole with nectary; c. detail of inflorescence, flower and fruit. d-g. Senna pendula var. glabrata - d. flowering branch; e. leaf; f. flower; g. fruit (Photographs a-d granted by Josimar P. Santos). 
da antera 1-1,3 mm compr., estaminódios ca. 5 mm compr.; ovário 0,9-1 cm compr., oblongoide, estilete 4-5 mm compr. Legumes 7,8-14 × 0,7-1 $\mathrm{cm}$, oblongos, planos, retos a ligeiramente curvos, castanho-claros a enegrecidos. Sementes 4-5 $\times$ 3-3,5 mm, oblongas a elipsoides.

Material examinado: Estrada de acesso a sede da FLONA em área antropizada, 20.XI.2013, fl., A.O. Souza et al. 45 (UFG).

Material examinado adicional: Mossâmedes, Parque Estadual da Serra Dourada: Sopé da Serra Dourada próximo ao córrego do Piçarrão na borda da estrada, em local perturbado, 02.III.2012, fl. e fr., M.M. Dantas 94 (UFG).

Espécie americana e amplamente distribuída no território brasileiro como ruderal em locais perturbados e como invasora em plantações (Irwin \& Barneby 1982; BFG 2015). Foi coletada em ambiente perturbado com flores e frutos de março a novembro.

Senna occidentalis pode ser facilmente reconhecida e diferenciada das demais espécies estudadas por ser a única com nectário no pecíolo e androceu com estame centro-abaxial vestigial, além das folhas com 4-6 pares de folíolos de ápice acuminado e racemos umbeliformes.

6. Senna pendula var. glabrata (Vogel) H.S. Irwin \& Barneby, Mem. New York Bot. Gard. 35: 382. 1982. Iconografia: Dantas \& Silva (2013, fig. $4 \mathrm{a}-\mathrm{d})$.

Fig. 4d-g

Arbustos 0,8-1,3 m alt., eretos, decumbentes ou apoiantes, e neste caso sobre plantas de até 6 m. Ramos cilíndricos, glabros a glabrescentes. Estípulas caducas. Folhas 4-9 cm compr.; pecíolo 1,8-4 cm compr., raque 2,3-6 cm compr.; folíolos 4-6 pares, 10-37 × 5-15 mm, obovais a oblongo-obovais, ápice obtuso, base oblíqua, glabros em ambas as faces, dicolores, face adaxial verde-escura, face abaxial verde-clara. Nectários 2-4 mm compr., globosos a subulados, sésseis a estipitados, entre o primeiro par de folíolos, raramente nos demais pares. Racemos 4-7 cm compr., típico, axilares e terminais com mais de 6 flores. Brácteas 3-5 mm compr., lanceoladas; botões globosos. Flores 1,8-4,5 cm compr., pedicelo 1-3,5 cm compr.; sépalas 9-14 × 4,5-7,5 mm, oblongo-obovais, amarelo-esverdeados, ápice obtuso; pétalas 1,3-2,1 ×0,8-1,7 mm, obovais, não maculadas; estames abaxias 3 , os latero-abaxiais 1,5-1,8 cm compr., o centro-abaxial $0,8-1 \mathrm{~cm}$ compr.; medianos $6,5-8 \mathrm{~mm}$ compr., rostro da antera 0,4-1,2 mm compr., estaminóides 4-5 mm compr.; ovário 5,9-6 mm compr., oblongoide, glabro; estilete 4-7 mm compr., glabro. Legumes 5-10 $\times 0,5-0,8 \mathrm{~cm}$, cilíndricos, oblongoides, verdeamarelados e lustrosos. Sementes 4-7 × 3-5 mm ovais a oblongo-elípticas, castanho-claras, lisas, bisseriadas.

Material examinado: Silvânia, FLONA, em meio ao cerrado s.str., 25.II.2012, fl., M.J. Silva 3441 (UFG); trilha oposta a entrada da sede, 13.III.2013, fl., A.O. Souza et al. 190 e 191 (UFG); trilha interativa, 14.III.2013, fl., A.O. Souza et al. 207 (UFG); trilha de frente a entrada a sede, 29.IV.2013, fl., A.O. Souza et al. 345 (UFG); morro ao norte da entrada da sede, 29.IV.2013, fr. A.O. Souza et al. 325 (UFG); imediações da mata a oeste da sede, próximo à fazenda, 25.V.2013, fl. e fr., A.O. Souza et al. 383 e 385 (UFG).

Espécie americana, sendo no Brasil reportada para todas as regiões em Campo Rupestre, Cerrado s.l., bordas de Florestas estacionais, litorâneas, ciliares e de galeria (Irwin \& Barneby 1982; BFG 2015). Na FLONA-Silvânia foi coletada em bordas de cerrado s.s. e Cerradão. Floresce de fevereiro a maio e frutifica de abril a maio.

Senna pendula var. glabrata diferenciase das demais espécies estudadas pelas folhas com 4-6 pares de folíolos, androceu com dois estames latero-abaxiais maiores que o centroabaxial, encurvados e voltados um para o centro da flor, além de frutos cilíndricos com sementes bisseriadas.

7. Senna rugosa (G. Don) H.S. Irwin \& Barneby, Mem. New York Bot. Gard. 35: 188. 1982. Iconografia: Dantas \& Silva (2013, fig. 5a-d).

Fig. 5a-c

Subarbustos a arbustos 1-2,2 m alt., eretos, cespitosos. Ramos, estípulas, pecíolo, raque, face externa das brácteas, pedicelo, e face externa das sépalas densamente tomentelos. Estípulas 4-8 mm compr., lanceoladas a lineares. Folhas 1,7-3,4 cm compr.; pecíolo 1-2,2 cm compr.; raque 1-1,7 cm compr.; folíolos 2 pares, 3-9,3 × 1,3-3,7 cm, oblongo-obovais a oblongo-elípticos, ápice agudo, base oblíqua, face adaxial glabra, face abaxial glabrescente a glabra, margem revoluta, superfície rugosa, cartáceos a coriáceos. Nectários 1-2,8 mm compr., ovóides, entre os dois pares de folíolos. Brácteas 3-5 × 1,1-2,8 mm., oval-lanceoladas. Racemos 4-12 cm compr., axilares e terminais, Flores 3,5-6,5 cm compr., assimétricas; pedicelo 3,2-4 cm compr.; sépalas 6-9 × 5-6 mm, obovais ou oblongo-elípticas, ápice arredondado, amareloesverdeado; pétalas 11-30 × 8-20 mm, obovais, oblongas ou oblonga-elípticas, a antero-lateral esquerda côncava,não maculadas; estames abaxiais 


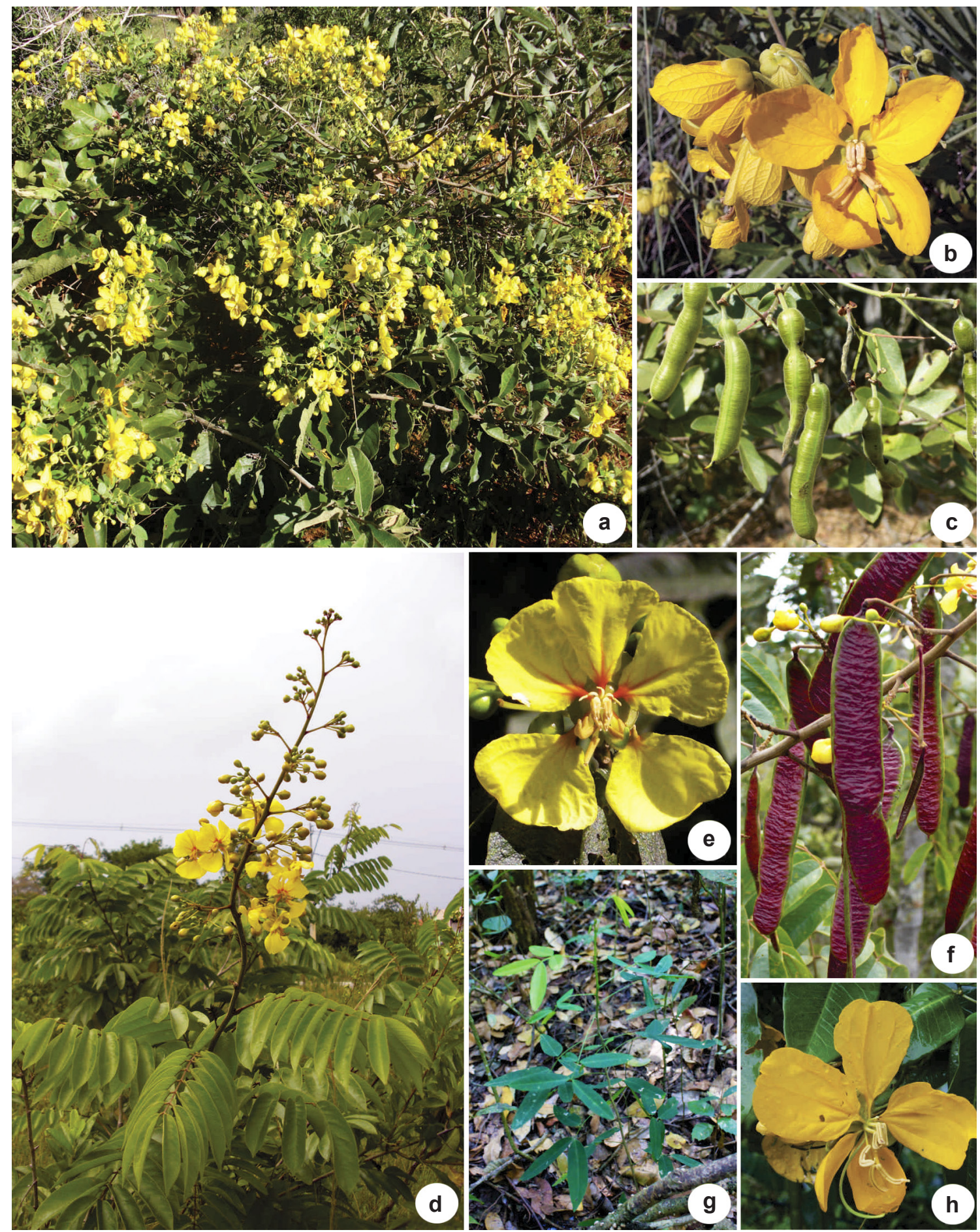

Figura 5 - a-c. Senna rugosa - a. ramo com flores; b. flor; c. fruto. d-f. Senna silvestris subsp. silvestris var. silvestris - d. ramo com flores; e. flor; f. fruto; g-h. Senna splendida - g. folha; h. flor (Fotos a e h concedidas por Josimar P. Santos).

Figure 5 - a-c. Senna rugosa - a. flowering branch; b. flower; c. fruit. d-f. Senna silvestris subsp. silvestris var. silvestris - d. flowering branch; e. flower; f. fruit; g-h. Senna splendida - g. leaf; h. flower. (Photos a and h granted by Josimar P. Santos). 
3,1-1,3 cm compr., semelhantes, medianos $0,7-1$ cm compr., rostro da antera 1,2-1,9 mm compr., estaminódios 4-7 mm compr.; ovário 10-13 $\times 0,8-1$ $\mathrm{mm}$ compr., oblongoide, velutino; estilete $5-8 \mathrm{~mm}$ compr. Legumes 7,5-10,2 × 1,5-2,2 cm, cilíndricos, enegrecidos quando maturo, flexíveis. Sementes 7-8 $\times 5-6 \mathrm{~mm}$, oblongas ou oblongo-elípticas, castanhoescuras, dispostas em duas séries.

Material examinado: Proximidades da trilha alternativa, 30.V.2012, fl., M.J. Silva \& Basilio J.P. 4261 (UFG); acima da porteira de ferro, 7.XII.2012, fr., A.O. Souza et al. 50 e 57 (UFG); Ao norte da entrada da sede, 4.II.2013., fl., A.O. Souza et al. 117 (UFG); trilha oposta a entrada da sede, 13.III.2013, fl. A.O. Souza et al. 189, 190 e 201 (UFG); trilha interativa, 29.IV.2013, A.O. Souza et al. 338 (UFG); morro ao lado direito na trilha de frente da sede, 29.IV.2013, fl., A.O. Souza et al. 322 e 346 (UFG); acima da porteira de ferro ao norte da sede, 24.V.2013, fr., A.O. Souza et al. 369 (UFG); trilha interativa, 25.V.2013, fl., A.O. Souza et al. 381 (UFG).

Espécie endêmica da América do Sul (Irwin \& Barneby 1982). No Brasil ocorre de norte a sul em áreas abertas no Cerrado s.l., Caatinga e em pastagem. Na FLONA-Silvânia é comumente encontrada em áreas abertas e borda do Cerrado s.s., com flores de maio a julho e frutos de julho a agosto.

Senna rugosa apresenta folhas com dois pares de folíolos, cartáceos a coriáceos com nervuras terciárias proeminentes, pecíolo menor que $2,5 \mathrm{~cm}$ e nectários nos dois pares de folíolos, além de frutos enegrecidos, cilíndricos e com duas séries de sementes, o que the permitem diferenciar de $S$. splendida, com a qual mais se relaciona morfologicamente conforme o comentário desta última.

8. Senna silvestris subsp. bifaria var. bifaria H.S. Irwin \& Barneby, Mem. New York Bot. Gard. 35: 94. 1982. Iconografia: Dantas \& Silva (2013, fig. 3e-g).

Fig. $5 \mathrm{~d}-\mathrm{f}$

Árvores 4-5 m alt. Ramos puberulentos a tomentelo-dourados, incluindo estípulas, pecíolo, raque, folíolos, eixo da inflorescência, face externa das brácteas e pedicelo. Estípulas 0,9-1,2 cm compr., lineares. Folhas 10-23 cm compr.; pecíolo 4,5-5,5(6,5) cm compr.; raque 13-19,5 cm compr.; folíolos 6-9 pares, 4,1-10,5 × 2-4 cm, oblongos ou oblongo-elípticos, ápice acuminado, base obtusa a ligeiramente cordada; discolores, face adaxial verdeescuro, face abaxial verde-opaca, cartáceos. Nectários ausentes. Panículas 18-37 cm compr., axilares ou terminais, eixos secundários corimbiformes. Brácteas 3-4 mm compr., lanceoladas. Flores 2,8-5 cm compr. zigomorfas; pedicelo 1,3-3 cm compr.; sépalas 6-10 $\times 4-8 \mathrm{~mm}$, oblongas a suborbiculares ou ovais, ápice obtuso, ciliadas, amarelo-castanhas; pétalas 1,4-1,8 $\times 1-1,5 \mathrm{~mm}$, obovais, ápice obtuso, emarginado ou truncado na pétala posterior, com mácula vermelha basal; estames abaxiais 3, 5-11 mm compr., semelhantes, medianos $4,5-7 \mathrm{~mm}$ compr., rostro da antera 0,4-1,1 mm compr., estaminódios 2,5-4 mm compr.; ovário 7-10 mm compr., oblongoide; estilete ca. $4 \mathrm{~mm}$ compr. Legumes 10-13,8 $\times 1,5-2,5$ $\mathrm{cm}$, planos, vináceos com bordos verde-escuros, conspicuamente venados. Sementes $3-9 \times 2-5 \mathrm{~mm}$, elíptico-oblongas a ovais, lisas, castanho escuras, dispostas em duas séries no fruto.

Material examinado: Trilha de frente a entrada da sede, 04.II.2013, fl., A.O. Souza \& R.C. Sodré 118 (UFG).

Material examinado adicional: Leolpodo de Bulhões na ponte da cachoeira, 14.III.2013, fl. e fr., A.O. Souza et al. 218 e 219 (UFG).

Táxon endêmico do Brasil, onde ocorre em todas as regiões em Cerrado $s . l$., pastagens, clareiras e bordas de Florestas Estacionais (Irwin \& Barneby 1982; Santos 2013). Na área de estudo foi encontrada nas bordas do Cerrado s.str. ao longo das trilhas, com flores em março.

Senna silvestris subsp. bifaria var. bifaria é caracterizada e diferenciada das demais espécies estudadas pela ausência de nectários foliares, flores com máculas vermelhas na base das pétalas, panículas com eixos secundários corimbiformes e frutos planos, vináceos, conspicuamente venados e com sementes arranjas em duas séries.

9. Senna splendida (Vogel) H.S. Irwin \& Barneby, Mem. New York Bot. Gard.35: 190. 1982.

Fig. 5g-h

Subarbustos $0,7-1,5 \mathrm{~cm}$ alt., decumbentes. Ramos delgados, estriados, puberulentos a glabros. Estípulas 1-3 × 0,5 mm, linear-lanceoladas ou subuladas, caducas. Folhas 3,2-6 cm compr.; pecíolo 2,5-4,1 cm compr.; raque $0,7-1,7 \mathrm{~cm}$ compr.; folíolos 2 pares, 2,7-7 × 0,9-2 $\mathrm{cm}$, elípticos, ápice agudo a obtuso, base ligeiramente oblíqua, discolores, face adaxial verde-escuro, face abaxial verde-clara opaco, membranáceos a papiráceos. Nectários 2-3 mm compr., subulados, presentes apenas no primeiro par de folíolos. Racemos 5-11 cm compr., corimbiformes, axilares com 2-4 flores, axilares. Brácteas 2,6-4 × 1,1-2 mm, lanceoladas, caducas. Flores 3-7 cm compr. assimétricas; sépalas $0,8-2 \times$ 0,4-1,1 cm, oblongo-elípticas ou ovais, ápice obtuso a acuminado; pétalas 2,7-4,5 × 1,8-3 cm, obovais a oblongo-elípticas, ápice arredondado a emarginado, a posterior emarginada a ligeiramente truncada e a antero-lateral direita côncava, não maculadas; estames abaxiais 3, 1,3-2,1 cm compr., semelhante, medianos 7,5-1,2 cm compr., rostro da antera $0-4$ 
mm compr., estaminódios 2-4 mm compr.; ovário 19-44 × 1-1,4 mm, velutino; estilete 4-5 mm compr. Legumes 17-22 × 05-0,7 cm, cilíndricos, retos a levemente curvos, marrom escuro. Sementes 4-4,3 × 2,7-3,3 mm, orbiculares, castanho escuras, lisas, arranjas em uma única série nos frutos.

Material examinado: Mata ao final da trilha interativa, 8.XII.2012, fl., A.O. Souza et al. 59 (UFG).

Senna splendida ocorre no Paraguai, Uruguai e Brasil (Irwin \& Barneby 1982), sendo neste último registrada nas regiões Nordeste, Centro-Oeste, Sudeste e Sul em Matas Ciliares ou de galerias, Floresta Ombrófila e Cerrado, entre 700-1300 m (Irwin \& Barneby 1982; Souza \& Santos 2015). Foi encontrada no interior da mata seca a leste da sede e trechos abertos próximos a curso d'água. Floresce em dezembro.

Senna splendida é mais relacionada morfologicamente à $S$. rugosa, pois ambas compartilham o mesmo número e forma dos folíolos. Entretanto, S. rugosa apresenta ramos rígidos, pecíolo $1-2,2 \mathrm{~cm}$ compr., folíolos coriáceos e nectários nos dois pares de folíolos, enquanto em $S$. splendida os ramos são delgados, o pecíolo 2,5-4,1 cm compr.,os folíolos são membranáceos a papiráceos e o nectário ocorre apenas no primeiro par de folíolos. Estas espécies diferem também quanto habitat, pois $S$. rugosa é típica de cerrado $s$. $l$. enquanto que $S$. splendida ocorre exclusivamente em mata.

\section{Agradecimentos}

Ao Instituto Chico Mendes de Conservação da Biodiversidade (ICMBio), a permissão para realizar o trabalho. Ao Renato Miranda, coordenador da Floresta Nacional de Silvânia, o apoio e suporte no trabalho de campo. À Universidade Federal de Goiás (UFG), o apoio logístico. E ao CNPq, a bolsa concedida ao primeiro autor.

\section{Referências}

Bentham, G. 1871. Cassia. In: Martius, C.F.P. von; Eichler, A.W. \& Urban. Flora brasiliensis, 15: 82-176.

BFG. 2015. Growing knowledge: an overview of Seed Plant diversity in Brazil. Rodriguésia 66: 1085-1113.
Bortoluzzi, R.L.C.; Miotto, S.T.S. \& Reis, A. 2007. Novos registros de Chamaecrista e Senna Mill. (Leguminosae-Caesalpinioideae) na flora sulbrasileira. Iheringia, Série Botânica 62: 121-130.

Dantas, M.M. \& Silva, M.J. 2013. O gênero Senna Mill. (Leguminosae, Caesalpinioideae, Cassieae) no Parque Estadual da Serra Dourada, GO, Brasil. Hoehnea 40: 99-113.

Dudik, N.M. 1981. Morphology of the pods of Leguminales (Fabales). In: Polhill, R.M. \& Raven, R. (eds.). Advances in legumes systematics 2. Royal Botanic Gardens, Kew. Pp. 897-901.

Irwin, H.S. \& Barneby, R.C. 1982. The American Cassiinae: a synoptical revision of Leguminosae - tribe Cassieae subtribe Cassinnae in the New World. Memoirs of the New York Botanical Garden 35: 1-918.

Köppen, W. 1948. Climatologia: com um estudio de losclimas de la Terra. F.C.E., Ciudad de México. 87p.

Lewis, G.P. 1987. Legumes of Bahia. Royal Botanic Gardens, Kew. 369p.

Lewis, G.P. 2005. Tribe Cassieae. In: Lewis, G.P.; Schrire, B.; Mackinder, B. \& Lock, M. (eds.). Legumes of the world. Royal Botanic Gardens, Kew. Pp. 111-161.

Lima, J.E.G. 1999. Os gêneros Cassia L. e Senna Mill. (Leguminosae: Caesalpinioideae: Cassieae) no estado de Pernambuco-Brasil. Dissertação de Mestrado. Universidade Rural de Pernambuco, Recife. $144 \mathrm{p}$.

Marazzi, B.; Endress, P.K.; Queiroz, L.P. \& Conti, E. 2006. Phylogenetic relationships winthin Senna (Leguminosae, Cassinae) based on three chloroplast regions: patterns in the evolution of floral symmetry and extrafloral nectaries. American Journal of Botany 93: 288-303.

Mori, S.A; Silva, L.A; Lisboa, G. \& Coradin, L. 1989. Manual de manejo do herbário fanerogâmico. Centro de Pesquisa do cacau, Ilhéus. 104p.

Queiroz, L.P. 2009. Leguminosas da caatinga. Universidade Estadual de Feira de Santana, Feira de Santana. 443p.

Rodrigues, R.S.; Flores, A.S.; Miotto, S.T.S. \& Baptista, L.R.M. 2005. O gênero Senna (Leguminosae, Caesalpinioideae) no Rio Grande do Sul, Brasil. Acta Botanica Brasilica 19: 1-16.

Santos, J.P. 2013. Sinopse taxonômica do gênero Senna Mill. (Leguminosae, Caesalpinioideae, Cassieae) para a região Centro-Oeste do Brasil. Dissertação de Mestrado. Universidade Federal de Goiás, Goiânia. 190p. 